\title{
Attitudinal and Mathematical Assessments as Measures of Student Success in a College General Chemistry II Course
}

\author{
LARRY KOLOPAJLO', Department of Chemistry, Eastern Michigan University, Ypsilanti, MI, USA.
}

ABSTRACT. This study reports results from administering unannounced attitudinal and mathematical assessments to 118 students, at the beginning of the term, in second-semester general chemistry classes (designed for science majors) at Eastern Michigan University. Testing was conducted during the 2010-2011 school year. The question to be answered was: which is more important in determining student course grades, attitudes toward chemistry and mathematics, or mathematical skill? The hypothesis was that attitudes and mathematical skill equally affect final course grade. A modified Wiebe instrument was selected to evaluate student attitudes toward chemistry and mathematics. To evaluate student mathematical skills, this study employed a mathematics assessment developed and performed at the University of Minnesota, and hence will be called the Minnesota Mathematics Assessment or MMA—a 20-question, multiple choice quiz designed for second-semester general chemistry students. Results were inter-correlated to determine what factors influenced student success. This study found a strong correlation between mathematics attitudes and chemistry attitudes, with a Pearson product-moment correlation coefficient $(r)$ of 0.50 . Between course grade vs. either chemical attitudes or mathematics attitudes, the $r$ values were 0.25 and 0.23 respectively, showing weak correlations. The correlation of course grade versus total MMA score gave an $r$ value of 0.35 , a moderate correlation. Comparison of the current study's MMA results with those of a previous Minnesota study demonstrates that the MMA is reproducible. The correlation coefficient found for course grade vs. total MMA score was comparable to that found in the Minnesota study. Analysis of the 20-question MMA data resulted in a 10-question subgroup whose $r=0.41$. Although some gender attitude differences were found, these did not correlate with course grade.

OHIO J SCI 119(2):17-27

\section{INTRODUCTION}

According to the Pew Research Center (2018), since 1990, US employment in STEM occupations increased from 9.7 million to 17.3 million, exceeding overall job growth. However, the Science and Engineering Indicators 2018 report issued by the National Science Board (NSB 2018) raised some concerns, namely that although the US has retained its role as global leader in STEM, China and other nations continue to present a formidable and rising challenge. Furthermore, within the field of chemistry, there is a generally recognized need to attract and graduate more chemistry professionals, especially from the reservoir of underrepresented groups.

Toward the goal of increasing student success in general chemistry - a course with a traditionally high failure rate-chemical educators (Tai et al. 2005; Widanski and McCarthy 2009) have investigated why students succeed or fail, and how students learn. Among the cognitive factors taken into account, mathematical preparation (Grove and Bretz 2007) is

${ }^{1}$ Address correspondence to Larry Kolopajlo, Professor of Chemistry, Department of Chemistry, Eastern Michigan University, Ypsilanti, MI 48197.

Email: lkolopajl@emich.edu known to be important. It is also recognized, however, that subjective- or non-cognitive variables (Eddy 2000), such as attitudes, play a role in determining student success. The objective of this study was to determine which is more important in determining student course grades in general chemistry II: attitudes toward chemistry and mathematics, or mathematical skill? The hypothesis was that the Minnesota Mathematics Assessment (MMA), a test of mathematical skills, would correlate with course grade at the same level as attitude survey results.

\section{The Concept of Attitude}

Although numerous investigators have contributed toward understanding the global concept of attitude, there is no consensus regarding a universal definition of the term. One well-known general definition of attitude (Eagly and Chaiken 2007) defines it as a psychological tendency that is expressed when a subject evaluates a particular object with some degree

2019 Kolopajlo. This article is published under a Creative Commons Attribution 4.0 International License ( https://creativecommons.org/licenses/by/4.0/) 
of favor or disfavor. The psychological tendency is the subject's response to a stimulus object. As one researcher (Osborne et al. 2003) wrote, attitudes are generally classified as affective, behavioral, or cognitive. Recognizable affective parameters (one's emotions or feelings toward an object) include: motivation, confidence, self-esteem, fear, anxiety, and enjoyment. On the other hand, cognitive attitudes symbolize a subject's beliefs, knowledge, and thoughts assigned to an object. Toward the objects of chemistry and mathematics, a person's (1) belief in the usefulness of either subject, (2) opinion of his/her ability to succeed in them, and (3) thoughts as to whether they are a male domain would be classified as cognitive attitudes.

Published research, such as described above, therefore shows that the concept of attitude consists of an open-ended set of mental constructs. For the purpose of this specific research investigation, attitude will be defined in operational terms (i.e., relative to the previously named mental constructs and the subject groups studied). Thus, in this study, attitude is defined as a subject's (student) positive or negative response to either chemistry or mathematics (objects) in the context of a general chemistry II (gen chem II) class. The mental constructs to be examined in this study include the affective attitudes of confidence and motivation, and the cognitive attitudes of success towards the objects, utility of the objects, and beliefs in the objects being a male domain. The following narrative discusses research studies that support the statement: "Student attitudes affect student performance in general chemistry classes."

Bauer (2005) used the definition that "attitude" is a mental construct that describes a subject's tendency to react negatively or positively to the discipline of chemistry. He noted that attitude models are still evolving through new work being published in the areas of personal and social cognition and in motivation. Moreover, Bauer commented that the construct "attitude to chemistry" may affect-and be affected by-student learning behaviors. To investigate the role of attitude in chemistry classes, Bauer $(2005,2008)$ designed both the 40-item Chemistry Self-Concept Inventory (CSCI) and the Attitude toward the Subject of Chemistry Inventory (ASCI). Bauer used his attitude survey instrument in an inquiry-based chemistry course for nonmajors and in a general chemistry I (gen chem I) course. It measured student attitudes regarding "chemistry" as a body of knowledge. His results showed science majors have lower anxiety and lower fear scores than non-science majors. In addition, students with less experience in chemistry displayed less emotional satisfaction, more anxiety, and viewed chemistry with less interest. Bauer also suggested that attitude studies are important because they provide snapshots on how students are responding to classes. According to Bauer, attitude studies provide another method for evaluating new pedagogical approaches that could result in increased student satisfaction. However, Bauer did not study how mathematical preparation affects chemistry course performance.

Using Bauer's self-concept inventory on gen chem I students, Lewis et al. (2009) — in a study with the title "Attitude Counts..."-found a direct relationship between higher self-concept and higher scores on the ACS (American Chemical Society) general chemistry exam (which served as the final exam in the course studied). Lewis and colleagues also found that students with high self-concept, and high self-concepts in both mathematics and chemistry, scored the highest among the groups studied. As a result, these authors stated that the affective domain plays an important role that is independent of traditional cognitive measures. Although Lewis et al. (2009) reported on attitudes, they did not look at relationships between attitude and mathematical skill. Moreover, there was no attempt to distinguish science majors from nonscience majors.

In another study, the Chemistry Attitudes and Experiences Questionnaire, or CAEQ (Coll et al. 2002), was designed to measure student attitudes toward first semester gen chem I. Findings suggested that general chemistry students possessed positive attitudes toward chemistry and preferred a structured learning environment. Results, however, indicated a weak correlation between course grade and attitude. Moreover, the subject group was science and engineering students, and mathematical skill was not considered.

Still another study (House 1995) reported on the attitudes of general chemistry students, and the predictive relationship between initial student attitudes and subsequent achievement in introductory chemistry — taken during the first year of college. It was found that noncognitive variables (namely academic achievement expectations and academic abilities) were better predictors of success than either admission ACT composite test scores or the number of years of high school mathematics. 


\section{The Role of Cognitive Factors}

The previous narrative focused on the role of affective variables in influencing student achievement in general chemistry courses; however, cognitive factors may also influence success. One cognitive variable is mathematical preparation and skill. For gen chem II, there are many important reasons for clarifying how mathematical preparation impacts student performance. A gen chem II class-which provides a foundation for further study in analytical and physical chemistry-utilizes mathematics extensively and (unlike gen chem I) requires considerable algebraic manipulations. For example, linear equations, their graphs, and the meaning of slope and intercept are used in zero-, first-, and second-order kinetics. Both natural and base-10 logarithms, as well as their inverse functions, are routinely employed in kinetics, acid/base chemistry ( $\mathrm{pH}, \mathrm{pK}_{\mathrm{a}}$, and the Henderson-Hasselbach equation), thermodynamics (free energy vs. equilibrium constant), and electrochemistry. Moreover, powers, roots, and polynomials are used in formulating models describing the equilibria of weak acids, weak bases, and slightly soluble salts.

The Pearson product-moment correlation coefficient, $r$, is often used to quantify the relationship between measured variables; in the current context these variables are mathematics achievement test scores and course grades. The parameter $r$ assesses the strength and direction of association between 2 continuous variables that are linearly related. The larger the absolute value of the coefficient, the stronger the relationship between the variables. For a perfect positive linear relationship, $r=+1$, while for a perfect negative linear relationship, $r=-1$. Conversely, when $r=0$, there is no relationship between the 2 variables. It is generally accepted (Pallant 2005) that weak, moderate, and strong correlations have $r$ values ranging from 0.10 to 0.29 , 0.30 to 0.49 , and 0.50 to 1.0 , respectively.

Studies into the relationship between mathematics achievement test scores and course grades in gen chem I were undertaken in the 1970s, and 3 published studies demonstrated significant relationships. For example, Pedersen (1975) reported a moderate correlation between SAT mathematics scores (MSAT) and freshman gen chem I course grades. In another study, Pickering (1975) found a strong positive correlation between MSAT scores and freshman chemistry grades-although he did not publish the correlation coefficient. Finally, Ozsogomonyan and Loftus (1979) reported a strong correlation $(r=0.51)$ between gen chem I grades and MSAT scores, but weak correlations $(r=0.21)$ between algebra assessment scores and gen chem I grades. None of these studies, however, considered attitude.

Bunce and Hutchinson (1993) studied a relatively small group of students $(n=181)$ in 3 different chemistry courses-1 course each for science majors, nonscience majors, and nursing chemistry students-to predict academic success in chemistry. They used a test known as the Group Assessment of Logical Thinking (GALT), along with SAT scores, to establish correlations with course grades (course grades were expressed as a student achievement score). These researchers found that for the science majors in their study (a small group of 50 students), the MSAT score better correlated with student achievement score $(\mathrm{r}=0.63)$ than did the GALT score $(r=0.38)$. However, student attitudes were not considered in this study.

More recently, Lewis and Lewis (2007) used the Test of Logical Thinking (TOLT), a test of formal reasoning ability, and MSAT scores to successfully identify at-risk students (defined as those underperforming in gen chem I). They reported strong correlations between MSAT scores and the TOLT $(r=0.65)$, and between MSAT and ACS exam scores $(r=0.61)$. However, Lewis and Lewis also noted that affective factors may influence student success.

MSAT scores are difficult to obtain. Therefore, the present study sought a short, quick, inexpensive, easily administered — and previously published — test to (1) assess student mathematical skills and (2) predict student success in gen chem II as a function of mathematical skills. Leopold and Edgar (2008a) (LE) developed and administered a 20-question University of Minnesota Mathematics Assessment (MMA) designed to measure basic mathematical fluency specifically involving skills directly utilized in gen chem II. They (Leopold and Edgar 2008b) showed that the LE-MMA test results compared to the GALT $(r=0.38)$ and to the California Chemistry Diagnostic Test $(r=0.42)$, the latter 2 tests both being employed in chemistry course placement and diagnostics. Their study could serve as an easily administered assessment instrument, but no studies have replicated it.

While some of the previously mentioned studies support the statements indicting student attitude 
has a large effect on student performance in general chemistry, other reviewed studies indicate mathematical preparation is more important. Such studies represent significant contributions to the literature, but they suffer from the disadvantages of being ambiguous, somewhat exploratory in nature, and not providing much data on gen chem II students. While published research addresses either attitudes or mathematical assessments, no indepth study has been able to correlate mathematical assessment with student attitudes toward chemistry and mathematics in gen chem II. The present study was performed to bridge that gap — and also to both test the reproducibility of the Leopold and Edgar (LE) study and determine whether mathematics and chemistry attitudes correlate with each other (and with gen chem II course grades).

\section{METHODS AND MATERIALS Course, Sample Group, and Tests}

Gen chem II, the chemistry course investigated in this report, is designed for science majors (especially those in chemistry and biology) and for others who have a background or interest in science. It also counts as a general education course, and therefore some students who are nonscience majors have been accepted into the class because of their previous college-preparatory work. For the course to count toward general education, or towards a science-major degree, students must attain a minimum grade of C. The course, organized according to the traditional ACS course model, employs much algebra.

The sample group in this study consisted of 118 gen chem II students (90\% Caucasian, 53\% female). This study, approved by an Institutional Review Board (IRB) and Protection of Human Subjects Committee, only used participants who voluntarily signed consent forms. Surveys and assessments-as described immediately below - were administered, without prior announcement, at the start of the term.

The LE-MMA, a calculator-free test completed in less than 30 minutes, consisted of 20 problems distributed over these sections: logarithms, scientific notation, graphs, and algebra. Refer to Leopold and Edgar (2008b) for further information.

Chemistry attitudes (CA) and mathematics attitudes (MA) were measured utilizing a modified Wiebe computer science survey (Wiebe et al. 2003). The Wiebe instrument, in turn, was based on the wellknown Fennema-Sherman mathematics attitudes scales (Fennema and Sherman 1976). Wiebe adapted the Fennema-Sherman mathematics instrument for use in the field of computer science by replacing the word mathematics with computer science.

In the present study, Wiebe's attitude survey instrument was modified for use in chemistry and mathematics by simply replacing the words computer science with either of the words mathematics or chemistry in the survey questions. The Wiebe survey uses 5 of the 7 subscale categories used in the Fennema-Sherman instrument. Two subscales measure affective attitudes: confidence in learning the object (either chemistry or mathematics) and motivation to learn it. The remaining 3 subscales measure cognitive attitudes: success toward the object, the object as a male domain, and usefulness of the object. The survey consists of 57 questions, the first question asking if the student intends to major in the subject (either chemistry or mathematics). The next 56 questions contain an equal number of questions phrased in positive and negative ways. Before being combined with positive answers, negative answers are reverse coded. The 56 questions in the survey cover the 5 subscales. Except for the motivation subscale that contains 8 questions, the remaining 4 subscales each contain 12 questions. The inventory utilizes a 5-point Likert scale with answer choices ranging from strongly agree ( 5 points) to strongly disagree (1 point).

\section{Data Analysis}

Linear regression was used to measure the relationship between student course grade and each of the following: total MMA score, total MMA score on each MMA section, and each individual MMA question. The regression coefficient between mathematics attitude and chemistry attitude was determined, for each student, by calculating the sum of the survey scores for all questions (2 to 57); this result was analyzed through linear regression using Minitab $^{\circledR}$. Likewise, to determine the correlation coefficient for confidence, the sum of survey scores for questions 2 to 13 were obtained for each student; chemistry confidence scores were then correlated with mathematics confidence scores. Similarly, linear regression was used to correlate mathematics attitude scores to chemistry attitude scores for each of the other subscales. The same procedure was used to correlate course grades with attitude scores. Data reduction was performed using Statistical Package for the Social Science (SPSS $\left.{ }^{\circledR}\right)$, Minitab, or Microsoft ${ }^{\circledR}$ Excel $^{\circledR}$. 


\section{RESULTS}

Results from all testing are presented in Tables 1 through 7 . Table 1 provides general demographic data. Table 2 compiles statistical data on the student MMA scores, where statistical data from left to right represent mean, median, and standard deviation $( \pm)$ of the mean respectively. The results of the Wiebe mathematics and attitude surveys are presented in Tables 3 and 4 respectively where the data entriesrelative to a 1 to 5 Likert scale-represent mean, median, and standard deviation $( \pm)$ of the mean. Tables 3 and 4 also provide the question numbers that are in the Wiebe attitude survey subscales. Table 5 presents course-grade distribution information, resolved from A (4.00) to $F(0.00)$. Table 6 provides Pearson correlation coefficients for the following: course grade vs. the chemistry attitude inventory results, course grade vs. the mathematical attitude inventory results, and mathematical attitude vs. chemical attitudes. On the other hand, Table 7 provides Pearson correlation coefficients-between course grade and each individual MMA questionfor both the present study and the LE study.

Wiebe used factor analysis to evaluate the validity of his survey (Williams et al. 2002); this analysis reported Cronbach's alpha values in the 0.83 to 0.91 range for each of the 5 subscales. In the present study, factor analysis gave Cronbach's alpha reliability estimates for confidence, success, gender, usefulness, and motivation respectively as: $0.93,0.79,0.80,0.93$, and 0.90 for chemistry attitudes, and $0.93,0.81$, $0.79,0.92$, and 0.92 for mathematics attitudes. The results of the present study show similarity to Wiebe's published results, thus demonstrating the reliability of the present study.

\section{MMA Scores}

As presented in Table 2, the measured MMA mean for all students was $11.0( \pm 3.5)$. Linear regression, applied to the course grade vs. MMA data, resulted in a correlation coefficient of $r=0.35$, indicating a moderate correlation. The mean MMA score for males at $11.4( \pm 3.3)$ is not significantly higher than for females at $10.6( \pm 3.6)$.

\section{Class Rank}

With respect to class rank, there were no differences in grade, MMA score, or total mathematics attitude score. The only difference found was that juniors showed a significantly higher chemistry attitude score of 4.22 vs. sophomores at 3.90.

\section{Attitudes}

Correlations between corresponding mathematics attitude and chemistry attitude categories were explored using Pearson correlation coefficients as summarized in Table 6 . These results reveal strong correlations between mathematics attitudes and chemistry attitudes $(r=0.50)$, but weak-yet significant - correlations between course grade and attitudes $(\mathrm{r}=0.21$ to 0.31$)$.

\section{DISCUSSION}

The preceding results allow several generalizations to be made. The main generalization is that mathematical skill correlates better with course grade than with attitude in gen chem II for this group of students. This statement is supported by the moderate correlation of the gen chem II course grade with MMA score $(r=0.35)$, but weak

Table 1

Student $(n=118)$ demographic data with respect to class rank and major

\begin{tabular}{lllllc}
\hline \hline & \multicolumn{5}{c}{ Class rank } \\
\cline { 2 - 6 } Data arrangement & Freshman & Sophomore & Junior & Senior & Degreed \\
\hline Percent of students & $5 \%$ & $26 \%$ & $31 \%$ & $30 \%$ & $8 \%$ \\
Number of students & 6 & 31 & 36 & 35 & 10
\end{tabular}

\begin{tabular}{llllll} 
& \multicolumn{5}{c}{ Major } \\
\cline { 2 - 5 } & Biology & Nonscience & $\begin{array}{l}\text { Biochemistry } \\
\text { \& chemistry }\end{array}$ & Education & $\begin{array}{l}\text { Other } \\
\text { sciences }\end{array}$ \\
\hline Percent of students & $36 \%$ & $23 \%$ & $20 \%$ & $7 \%$ & $14 \%$ \\
Number of students & 43 & 27 & 23 & 9 & 16 \\
\hline
\end{tabular}


Table 2

Student MMA scores expressed in the order: mean, median, standard deviation ( \pm ) of the mean

\begin{tabular}{lrlllll}
\hline \hline $\begin{array}{l}\text { Student } \\
\text { sample }\end{array}$ & \multicolumn{1}{l}{$\begin{array}{l}\text { Total } \\
\text { score } \\
\text { (20 questions) }\end{array}$} & Logarithms & $\begin{array}{l}\text { Scientific } \\
\text { (7 questions) }\end{array}$ & $\begin{array}{l}\text { Gotation } \\
\text { (5 questions) }\end{array}$ & (4 questions) & (4 questions) \\
\hline All & $(\mathrm{n}=118)$ & $11.0,10.0,3.5$ & $3.0,3.0,1.8$ & $3.9,4.0,0.9$ & $2.1,2.0,1.1$ & $2.0,1.4,2.0$ \\
Female & $(\mathrm{n}=62)$ & $10.6,10.0,3.6$ & $2.7,2.0,1.9$ & $3.8,4.0,1.0$ & $2.1,2.0,1.1$ & $2.0,2.0,1.3$ \\
Male & $(\mathrm{n}=56)$ & $11.4,11.0,3.3$ & $3.3,3.0,1.7$ & $4.0,4.0,0.7$ & $2.0,2.0,1.0$ & $2.0,2.0,1.4$ \\
\hline
\end{tabular}

Table 3

Mean Wiebe mathematics (math) attitude (MA) inventory results in the order: mean, median, and standard deviation $( \pm)$ of the mean ${ }^{\text {a }}$

\begin{tabular}{|c|c|c|c|c|c|c|}
\hline $\begin{array}{l}\text { Math attitude- } \\
\text { student sample }\end{array}$ & $\begin{array}{l}\text { Total } \\
\text { mean } \\
\text { score }\end{array}$ & $\begin{array}{l}\text { Confidence } \\
\text { in learning } \\
\text { math }\end{array}$ & $\begin{array}{l}\text { Success } \\
\text { in math }\end{array}$ & $\begin{array}{l}\text { Math } \\
\text { as a male } \\
\text { domain }\end{array}$ & $\begin{array}{l}\text { Usefulness } \\
\text { of math }\end{array}$ & $\begin{array}{l}\text { Effective } \\
\text { motivation } \\
\text { in math }\end{array}$ \\
\hline$(\mathrm{n}=118)$ & $4.2,4.3,0.5$ & $4.1,4.2,0.8$ & $4.4,4.5,0.5$ & $4.5,4.7,0.6$ & $4.4,4.5,0.6$ & $3.9,4.0,0.8$ \\
\hline$(\mathrm{n}=62)$ & $4.2,4.3,0.5$ & $4.0,4.2,0.8$ & $4.5,4.5,0.5$ & $4.6,4.8,0.5$ & $4.4,4.5,0.7$ & $3.9,4.0,0.8$ \\
\hline$(\mathrm{n}=56)$ & $4.2,4.3,0.5$ & $4.2,4.3,0.7$ & $4.4,4.5,0.5$ & $4.4,4.5,0.6$ & $4.4,4.4,0.6$ & $3.9,4.0,0.8$ \\
\hline Question nos. ${ }^{b}$ & $2-57$ & $2-13$ & $14-25$ & $26-33$ & $34-45$ & $46-57$ \\
\hline
\end{tabular}

Table 4

Mean Wiebe chemistry (chem) attitude (CA) inventory results in the order: mean, median, and standard deviation $( \pm)$ of the mean ${ }^{\text {a }}$

\begin{tabular}{lllllll}
\hline \hline $\begin{array}{l}\text { Chem attitude- } \\
\text { student sample }\end{array}$ & $\begin{array}{l}\text { Total } \\
\text { mean } \\
\text { score }\end{array}$ & $\begin{array}{l}\text { Confidence } \\
\text { in learning } \\
\text { chem }\end{array}$ & $\begin{array}{l}\text { Success } \\
\text { in chem }\end{array}$ & $\begin{array}{l}\text { Chem } \\
\text { as a male } \\
\text { domain }\end{array}$ & $\begin{array}{l}\text { Usefulness } \\
\text { of chem }\end{array}$ & $\begin{array}{l}\text { Effective } \\
\text { motivation } \\
\text { in chem }\end{array}$ \\
\hline All $\quad(\mathrm{n}=118)$ & $4.1,4.1,0.5$ & $3.8,3.1,0.8$ & $4.3,4.4,0.6$ & $4.5,4.5,0.6$ & $4.3,4.5,0.7$ & $3.6,3.5,0.9$ \\
Female $\quad(\mathrm{n}=62)$ & $4.1,4.0,0.5$ & $3.6,3.8,0.9$ & $4.4,4.5,0.5$ & $4.6,4.8,0.5$ & $4.3,4.5,0.7$ & $3.5,3.3,1.0$ \\
Male $\quad(\mathrm{n}=56)$ & $4.1,4.1,0.5$ & $4.0,4.1,0.7$ & $4.4,4.6,0.6$ & $4.2,4.5,0.8$ & $4.2,4.5,0.8$ & $3.7,3.6,0.7$ \\
Question nos. ${ }^{\mathrm{b}}$ & $2-57$ & $2-13$ & $14-25$ & $26-33$ & $34-45$ & $46-57$ \\
\hline \multicolumn{2}{l}{${ }^{2}$ Data entries relative to a 1 to 5 Likert scale. } & \multicolumn{2}{l}{ b Question numbers in the Wiebe attitude survey subscales. }
\end{tabular}

Table 5

Student mean course grade (GPA) and grade distribution ${ }^{\mathrm{a}}$

\begin{tabular}{lllllll}
\hline \hline \multicolumn{2}{l}{ Student sample } & Mean grade & A/A- & B+/B/B- & C+/C & Below C \\
\hline All & $(\mathrm{n}=118)$ & $2.28 \pm 1.2$ & $18.64 \%$ & $26.27 \%$ & $33.90 \%$ & $21.19 \%$ \\
Female $\quad(\mathrm{n}=62)$ & $2.17 \pm 1.3$ & $19.35 \%$ & $20.97 \%$ & $35.48 \%$ & $24.19 \%$ \\
Male & $(\mathrm{n}=56)$ & $2.41 \pm 1.2$ & $17.86 \%$ & $32.14 \%$ & $32.14 \%$ & $17.86 \%$ \\
\hline
\end{tabular}

${ }^{\mathrm{a}}$ Grades resolved from A (4.00) to F (0.00). 
Table 6

Pearson correlation coefficients ( $r$ ) between course grades (GPA) and chemistry attitude (CA) or mathematics attitude (MA) survey scores

\begin{tabular}{lllllll}
\hline \hline $\begin{array}{l}\text { Interrelationship } \\
\text { student sample }\end{array}$ & $\begin{array}{l}\text { Total } \\
\text { attitude } \\
\text { score }\end{array}$ & $\begin{array}{l}\text { Confidence } \\
\text { in learning } \\
\text { subject }\end{array}$ & $\begin{array}{l}\text { Attitude } \\
\text { toward } \\
\text { success }\end{array}$ & $\begin{array}{l}\text { Subject } \\
\text { as male } \\
\text { domain }\end{array}$ & $\begin{array}{l}\text { Usefulness } \\
\text { of subject }\end{array}$ & $\begin{array}{l}\text { Effective } \\
\text { motivation } \\
\text { in subject }\end{array}$ \\
\hline $\begin{array}{l}\text { Grade vs. CA } \\
\text { All }\end{array}$ & $0.25^{* *}$ & $0.38^{* *}$ & 0.02 & 0.06 & 0.04 & $0.26^{* *}$ \\
$\quad$ Female & 0.20 & $0.29^{*}$ & 0.09 & 0.06 & 0.12 & 0.22 \\
$\quad \begin{array}{l}\text { Male } \\
\text { Grade vs. MA }\end{array}$ & $0.31^{*}$ & $0.51^{* *}$ & 0.20 & 0.25 & 0.05 & $0.30^{*}$ \\
All & & & & & & \\
Female & $0.23^{*}$ & $0.21^{*}$ & 0.13 & 0.03 & 0.17 & $0.22^{*}$ \\
Male & 0.24 & $0.30^{*}$ & 0.05 & 0.05 & 0.20 & $0.26^{*}$ \\
CA vs. MA & 0.21 & 0.12 & 0.25 & 0.15 & 0.13 & 0.16 \\
All & & & & & & \\
Female & $0.50^{* *}$ & $0.32^{* *}$ & $0.55^{* *}$ & $0.54^{* *}$ & $0.42^{* *}$ & $0.48^{* *}$ \\
Male & $0.50^{* *}$ & 0.25 & $0.63^{* *}$ & $0.42^{* *}$ & $0.61^{* *}$ & $0.54^{* *}$ \\
\hline
\end{tabular}

* Significant at $\alpha=0.05$.

** Significant at $\alpha=0.01$.

Table 7

Pearson correlation coefficients ( $r$ ) between course grade and each MMA question in each MMA section. Results are presented for both the present study and the LE study.

\begin{tabular}{|c|c|c|c|c|c|c|c|}
\hline \multirow[t]{2}{*}{ Study } & \multicolumn{7}{|c|}{ Logarithm section: question numbers (No.) 1 to 7} \\
\hline & No. 1 & No. 2 & No. 3 & No. 4 & No. 5 & No. 6 & No. 7 \\
\hline Present & 0.22 & -0.01 & 0.12 & 0.07 & 0.06 & 0.36 & -0.03 \\
\hline \multirow[t]{3}{*}{ LE } & 0.22 & 0.20 & 0.21 & 0.22 & 0.12 & 0.21 & 0.09 \\
\hline & \multicolumn{7}{|c|}{ Scientific notation section: question numbers (No.) 8 to 12} \\
\hline & No. 8 & No. 9 & No. 10 & No. 11 & No. 12 & & \\
\hline Present & 0.15 & 0.25 & 0.05 & -0.01 & 0.18 & & \\
\hline \multirow[t]{3}{*}{ LE } & 0.01 & 0.04 & -0.07 & 0.19 & 0.04 & & \\
\hline & \multicolumn{7}{|c|}{ Graphing section: question numbers (No.) 13 to 16} \\
\hline & No. 13 & No. 14 & No. 15 & No. 16 & & & \\
\hline Present & 0.06 & 0.07 & 0.29 & 0.08 & & & \\
\hline \multirow[t]{3}{*}{ LE } & 0.18 & 0.07 & 0.20 & 0.20 & & & \\
\hline & \multicolumn{7}{|c|}{ Algebra section: question numbers (No.) 17 to 20} \\
\hline & No. 17 & No. 18 & No. 19 & No. 20 & & & \\
\hline Present & 0.10 & 0.22 & 0.25 & 0.29 & & & \\
\hline LE & 0.16 & 0.08 & 0.19 & 0.22 & & & \\
\hline
\end{tabular}

Present: questions 6, 9, 15, 16, 19, and 20 are significant at $\mathrm{p}<0.01$.

Present: questions 1 and 18 are significant at $\mathrm{p}<0.05$.

LE: questions $1-4,6,11,13,15-17,19$, and 20 are significant at $\mathrm{p}<0.005$. 
correlation with attitude scores $(r=0.25)$. This statement is rationalized by the extensive use of algebra, logarithms, exponentials, and conceptually difficult problems encountered in gen chem II. These results also appear to extend Coll's results that grade weakly correlates to attitude in a study on gen chem I students. Therefore, to promote student success, instructors should focus more on mathematics instruction and less on attitude. Instructors can, for example, not only require students to complete mathematic prerequisites, but also consider changing to more advanced ones.

The second major generalization of this study is that chemistry attitude inventory scores correlated strongly with mathematics attitude scores $(r=0.50)$, indicating that these variables and their dynamics of operation are similar. Results for the mathematics attitude subscales showed this trend:

Motivation $<$ Confidence $<$ Success $<$ Usefulness $<$ Male

Chemistry attitudes subscales ranked in the same order, except that usefulness and success were reversed. Comparing chemistry attitudes to mathematics attitudes, it is found that the overall mathematics attitude mean is higher than the chemistry attitude mean value; this is in part due to the scores on the confidence and motivation subscales being significantly higher on the mathematics attitude scale. It is therefore possible to surmise that students are more chemophobic than math-phobic. The result that juniors showed a significantly higher chemistry attitude score of 4.22 vs. sophomores at 3.90 probably relates to their higher maturity and increased academic experience.

The third major generalization inferred from the data is that students overestimated their potential for success. For example, the mean MMA score for all participants is only 11.0 (55\% correct) but the mean mathematics attitude score is relatively high at 4.23 ( $85 \%$ on a 1 to 5 scale). In addition, the average course grade is 2.28 (57\% of students, where $\mathrm{C}+=2.3)$ but the total mean chemistry attitude score is 4.08 ( $82 \%$ of students). Student demographics may explain this result. Table 1 demonstrates that the student population in the present study is mainly upperclassmen: about $70 \%$ of students are at the junior level or above. In contrast, in the Minnesota study, only about $20 \%$ of students were upperclassmen. In order to counteract this overconfidence effect, instructors should emphasize that daily work is key to success. Instructors should also give students a mathematics pretest, a mathematics review sheet at the beginning of the course, and mathematical help thereafter. Early intervention through tutoring sessions or videos on mathematics may help students succeed once the course is in session.

The fourth generalization is that there were some differences between males and females with respect to 2 of the chemistry attitude subscales. Males have higher confidence scores. In addition, although both males and females believe that chemistry is a male domain, a significantly higher number of females than males attest to this belief. However, the mean course grade as a GPA of 2.41 for males was not found to be statistically different than the mean course grade of 2.17 for females because $p=0.282$ $>0.05$. Likewise, there are no significant differences with respect to overall mathematics or chemistry attitude scores between males and females.

Because science majors comprise about $75 \%$ of the student population in the present study, results are therefore skewed toward them.

\section{Comparison with the LE Minnesota Study}

In the present study, the measured MMA mean of $11.0( \pm 3.5)$ is markedly lower than the Minnesota average of $13.9( \pm 3.4)$ at the $99 \%$ confidence level, indicating a gap in mathematical skill level. Also the mean MMA score for males at $11.4( \pm 3.3)$ is not significantly higher than for females at $10.6( \pm 3.6)$. In contrast, the Minnesota study showed that the male MMA average of $14.5( \pm 3.5)$ was markedly higher than females at $13.3( \pm 3.0)$, but this difference was not explained.

In the present study, the linear regression results for course grade versus MMA score-for all students over the complete 20-question MMA- gave $\mathrm{r}=0.35$. The square of the correlation coefficient, $\mathrm{r}^{2}=0.12$, indicates that $12 \%$ of the variation in course grade is predictable from MMA score. On the other hand, in the Minnesota study the course grade versus MMA score was $r=0.38$, giving $r^{2}=0.14$; an indication that $14 \%$ of the variation in course grade is predictable from MMA score (as published in Leopold and Edgar 2008b). Results between the 2 studies are thus comparable, supporting the use of the MMA as a diagnostic instrument. However, insufficient data are available to use the MMA as a standardized test instrument. 


\section{MMA Question and Subgroup Comparisons}

Table 7 compares rvalues between the course grade and each individual MMA question for the present study versus the LE study. The LE study selected questions with the highest $r$ values (in the 0.16 to 0.22 range) and obtained a 12-question MMA subgroup which included questions: 1 through 4 and 6 on logarithms; 11 on scientific notation; 13 , 15, 16 on graphing; and 17, 19, 20 on algebra. For this 12-question subgroup, they obtained $r=0.41$ at the $\mathrm{p}<0.001$ level. However, this result is not much higher than the r value of 0.38 obtained using the entire 20-question MMA. The present study, applying this method using the same 12-question subgroup, gave $r=0.35$.

In the present study, however, analysis of the Pearson correlation coefficients showed that questions 2 and 4 should be excluded from the present study's 12-question subgroup because of low r values. Using the 10 remaining questions created a subgroup containing questions $1,3,6,8,9,12,15$, and 18 through 20 . It contained only 6 questions matching those in the LE study $(1,3,6,15,19$, $20)$. When course grade was correlated against this MMA 10-question subgroup, for the data in the present study, it was found that $r=0.44$ at $p<0.005$; close to the 12-question MMA subgroup of LE for which $r=0.41$ at $p<0.001$. Hence, the MMA was reproducible in the present study, but with a different question subgroup. Perhaps these differences are due to differences in the sample populations.

\section{Predictive Relationship: Course Grade vs. MMA Score}

For their 12-question subset, LE then determined the relationship between total MMA score and course grade as follows: first, they pooled together all students having the same MMA score, and computed the average course grade for that data set; second, they found a linear relationship between course grade and mean MMA score. LE reported a slope of 0.14 and intercept of 1.63 , with a linear fit. In the present study, the same method also gave a linear fit (slope $=0.31$, intercept $=0.52$ ) for the 10 -question subset used in this study. Since each mean LE-MMA score contained 15 to 40 students per point, an accurate prediction of course grade was not possible. Moreover, using a MMA score of 10 in the LE study would result in a grade (expressed as a GPA) of 3.03; in the present study, a MMA score of
10 gives a grade of 3.62 . Thus, the predictive method just described is not statistically valid because, for example, it is unweighted and inflates correlations.

It is also of interest to analyze $r$ values correlating course grades with MMA section score in the present study. Regression analysis of course grade with each MMA section gave these $r$ values: logarithms, 0.21 ; scientific notation, 0.19 ; graphing, 0.21 ; and algebra, 0.29 . The highest correlation is obviously associated with algebra. To rationalize this result it must be understood that, on classroom exams in this gen chem II course, logarithms could be computed with a calculator. Additionally, although significant figures and scientific notation were often used, point deductions for such errors were numerically much smaller than point deductions for incorrect use of algebra. Finally, graphs were seldom used on examinations. It is not surprising that, in the present study, only the MMA algebra subsection moderately correlated with course grade. However, without knowing the structure of the LE Minnesota study, it is impossible to explain how course grades correlated with individual MMA sections in that study.

\section{Course Comparisons}

There are several important differences between the present study and the LE study. First and foremost, in the LE study, 20\% of the course grade was based on lab. In the present study the entire course grade was derived from lecture, about $95 \%$ of which was based on exams and quizzes. Thus, in the LE study, some students who may have done poorly in lecture could have raised their lecture grades through lab; this would skew results toward higher grades. In the LE supplementary material (Leopold and Edgar 2008b) it is noted that average exam grades ranged from $62 \%$ to $67 \%$ across 3 instructors, whereas the average lab grade was much higher at $88 \%$. Therefore, the LE course grade was moderately impacted by lab. In the present study, since lab was a course independent of lecture, there was no such effect.

Second, in the LE study, extra credit was offered. LE noted, for example, that compared to men, women were more likely to take advantage of extra credit assignments - and they also performed better in lab. This resulted in women having slightly higher grades than men. In contrast, in the present study, since extra credit assignments were not an option, these factors did not inflate student grades. 
Third, in the LE study, students could use programmable/graphing calculators on examinations, but these were banned for exams in the present study. It is well known that programmable calculators can store equations and notes, and some contain an interactive periodic table. Programmable calculators can also calculate significant figures and make unit conversions. In addition, computer programswhich automatically perform calculations such as the $\mathrm{pH}$ of a strong or weak acid-can be downloaded onto programmable calculators. It seems that the LE study partly defeated the purpose of their calculator-free mathematics assessment by allowing students to use programmable calculators on exams. It is also worth mentioning that, for the examinations used in the present study, students were not allowed to bring equation sheets or cheat sheets as references. Although a few equations were provided-such as integrated rate laws-for the most part students were on their own.

Finally, another unknown difference between the LE study and the present study was the nature of exams. In the present study, students took four, 75-minute, non-multiple-choice, exams and a multiple-choice final exam; therefore, on the 75-minute exams, students had to demonstrate the mathematical steps used to obtain answers.

\section{CONCLUSION}

This study reported results obtained from administering attitudeand mathematics assessments to gen chem II students. It was found that course grade correlated moderately with mathematical skill but weakly with attitude. The course grade vs. mathematics assessment correlation results presented in the present study are more authentic than the earlier LE study; because, in the present study, course grade did not depend on lab scores, and because programmablecalculators were banned on examinations. Recently, at the institution where this study was performed, college algebra was invoked as a prerequisite for gen chem II (rather than as a corequisite). Since the LE study did not measure attitudes, the attitude data in the present report represent new knowledge.

\section{ACKNOWLEDGEMENTS}

This work was supported by the Eastern Michigan University Department of Chemistry. The author thanks Dr. Joseph Scazzero, Professor of Decision Sciences at Eastern Michigan University, for reviewing the statistical work and recommending improvements. Thanks also to Professor Timothy Brewer of the Department of Chemistry for helping to administer the MMA.

\section{LITERATURE CITED}

Bauer CF. 2005. Beyond "student attitudes": chemistry selfconcept inventory for assessment of the affective component of student learning. J Chem Educ. 82(12):1864-1870. https://doi.org/10.1021/ed082p1864

Bauer CF. 2008. Attitude towards chemistry: a semantic differential instrument for assessing curriculum impacts. J Chem Educ. 85(10):1440-1445. https://doi.org/10.1021/ed085p1440

Bunce DM, Hutchinson KD. 1993. The use of the GALT (Group Assessment of Logical Thinking) as a predictor of academic success in college chemistry. J Chem Educ. 70(3):183-187 https://doi.org/10.1021/ed070p183

Coll RK, Dalgety J, Salter D. 2002. The development of the chemistry attitudes and experiences questionnaire (CAEQ). Chem Educ Res Pract. 3(1): 9-32. https://doi.org/10.1039/B1RP90038B

Eagly AH, Chaiken S. 2007. The advantages of an inclusive definition of attitude. Soc Cognition. 25(5):582-602. Special Issue: What is an Attitude? https://doi.org/10.1521/soco.2007.25.5.582

Eddy RM. 2000. Chemophobia in the college classroom: extent, sources, and student characteristics. J Chem Educ. $77(4): 514-517$. https://doi.org/10.1021/ed077p514

Fennema E, Sherman JA. 1976. Fennema-Sherman mathematics attitudes scales: instruments designed to measure attitudes toward the learning of mathematics by females and males. J Res Math Educ. 7(5):324-326. https://doi.org/10.2307/748467

Grove N, Bretz SL. 2007. CHEMX: an instrument to assess students' cognitive expectations for learning chemistry.

J Chem Educ. 84(9):1524-1529. https://doi.org/10.1021/ed084p1524

House JD. 1995. Noncognitive predictors of achievement in introductory college chemistry. Res High Educ. 36(4):473-490. https://doi.org/10.1007/BF02207907

Leopold DG, Edgar B. 2008a. Degree of mathematics fluency and success in second-semester introductory chemistry. J Chem Educ. 85(5):724-731. https://doi.org/10.1021/ed085p724 
Leopold DG, Edgar B. 2008b. Degree of mathematics fluency and success in second-semester introductory chemistry [located in addendum titled: Supporting information]. J Chem Educ. 85(5):724-731. https://doi.org/10.1021/ed085p724

Lewis SE, Lewis JE. 2007. Predicting at-risk students in general chemistry: comparing formal thought to a general achievement measure. Chem Educ Res Pract. 8(1):32-51.

https://doi.org/10.1039/B6RP90018F

Lewis SE, Shaw JL, Heitz, JO, Webster, GH. 2009. Attitude counts: self-concept and success in general chemistry. J Chem Educ. 86(6):744-749. https://doi.org/10.1021/ed086p744

[NSB] National Science Board (US). 2018. Science and engineering indicators 2018. [accessed 2018 Nov 18]. NSB2018-1. https://www.nsf.gov/statistics/2018/nsb20181/

Osborne J, Simon S, Collins S. 2003. Attitudes towards science: a review of the literature and its implications. Int J Sci Educ. 25(9):1049-1079. https://doi.org/10.1080/0950069032000032199

Ozsogomonyan A, Loftus D. 1979. Predictors of general chemistry grades. J Chem Educ. 56(3):173-175. https://doi.org/10.1021/ed056p173

Pallant J. 2005. SPSS survival manual: a step by step guide to data analysis using SPSS for Windows. New York: Open University Press. 126.

Pedersen LG. 1975. The correlation of partial and total scores of the scholastic aptitude test of the college entrance examination board with grades in freshmen chemistry. Educ Psychol Measurem. 35(2):509-511. https://doi.org/10.1177\%2F001316447503500238
Pew Research Center. 2018. 7 facts about the STEM workforce. [updated 2018 Jan 9; accessed 2018 Nov 18]. https://www.pewresearch.org/fact-tank/2018/01/09/7-factsabout-the-stem-workforce/

Pickering M. 1975. Helping the high risk freshman chemist. J Chem Educ. 52(8):512-514. https://doi.org/10.1021/ed052p512

Tai RH, Sadler PM, Loehr JF. 2005. Factors influencing success in introductory college chemistry. J Res Sci Teach. 42(9):987-1012. https://doi.org/10.1002/tea.20082

Widanski BB, McCarthy WC. 2009. Assessment of chemistry anxiety in a two-year college. J Chem Educ. 86(12):1447-1449. https://doi.org/10.1021/ed086p1447

Wiebe E, Williams LA, Yang K, Miller CS. 2003. Computer science attitude survey. Raleigh (NC): North Carolina State University, Department of Computer Science. 5 p. Technical Report: TR-2003-01. https://repository.lib.ncsu.edu/handle/1840.4/778

Williams L, Wiebe E, Yang K, Ferzli M, Miller C. 2002. In support of paired programming in the introductory computer science course. Comput Sci Educ. 12(3):197-212.

https://doi.org/10.1076/csed.12.3.197.8618 